\title{
Simultaneous dislocation of the radial head and distal radio-ulnar joint without fracture in an adult patient: a case report and review of literature
}

\author{
Xiang-Yun $\operatorname{Jin}^{1 \dagger} \mathbb{D}$, Wen-Bo Zhao ${ }^{1 \dagger} \mathbb{D}$, Yu-Qi Dong ${ }^{1^{*}}$ (I) and Yi-Gang Huang ${ }^{2^{*}}$ (D)
}

\begin{abstract}
Background: Simultaneous dislocation of the radial head and distal radio-ulnar joint without fracture (Criss-Cross Injury) in an adult patient is rarely reported in previous studies. The pathological changes and injury patterns have not been clearly demonstrated.

Case presentation: A 26-year-old woman presented with acute pain of the right wrist and elbow after a fall from cycling. Physical examination revealed an unstable elbow and wrist joint. Plain radiographs showed volar dislocation of the radial head and dorsal dislocation of the distal radius without associated fracture, forming a crisscross appearance of the ulna and radius on the lateral radiograph. MRI images confirmed partial rupture of the proximal interosseous membrane from its dorsal attachment on the radius, as well as partial rupture of the medial collateral ligament. Conservative treatment failed because the radiocapitellar joint and distal radio-ulnar joint could not be simultaneously reduced. Surgical exploration revealed a highly unstable radial head, but the annular ligament was found to be intact. Manual force was applied to reduce the radial head and a percutaneous K-wire was used to stabilize the proximal radioulnar joint with the forearm in full supination. After surgery, the elbow was immobilized in $90^{\circ}$ flexion by a long arm cast for 4 weeks. The K-wire was removed at 6 weeks postoperatively. At 18 months postoperatively, the patient had regained a full range of flexion and extension, with normal supination and a slight limitation in pronation.
\end{abstract}

Conclusions: The proximal IOM, especially the dorsal band, was injured in Criss-Cross injuries, while the central part of the IOM remained intact. This injury pattern distinguished itself from Essex-Lopresti injury, which mainly involves rupture of the central band of the IOM.

Keywords: Forearm injuries, Soft tissue injuries, Joint instability, Case report

\footnotetext{
* Correspondence: dyqrigk@126.com; huangyigang@126.com

'Xiang-Yun Jin and Wen-Bo Zhao contributed equally to this work.

'Department of Orthopedic Trauma, Renji Hospital, School of Medicine,

Shanghai Jiao Tong University, Shanghai 200127, People's Republic of China

${ }^{2}$ Department of Orthopedic Surgery, Shanghai Jiao Tong University Affiliated

Sixth People's Hospital, 200233 Shanghai, People's Republic of China
}

C C The Author(s). 2020 Open Access This article is licensed under a Creative Commons Attribution 4.0 International License, which permits use, sharing, adaptation, distribution and reproduction in any medium or format, as long as you give appropriate credit to the original author(s) and the source, provide a link to the Creative Commons licence, and indicate if changes were made. The images or other third party material in this article are included in the article's Creative Commons licence, unless indicated otherwise in a credit line to the material. If material is not included in the article's Creative Commons licence and your intended use is not permitted by statutory regulation or exceeds the permitted use, you will need to obtain permission directly from the copyright holder. To view a copy of this licence, visit http://creativecommons.org/licenses/by/4.0/ The Creative Commons Public Domain Dedication waiver (http://creativecommons.org/publicdomain/zero/1.0/) applies to the data made available in this article, unless otherwise stated in a credit line to the data. 


\section{Background}

Simultaneous dislocation of the radial head and distal radio-ulnar joint without fracture in an adult patient is rarely reported in previous studies with only 7 documented cases [1-7]. The typical radiographic changes involve volar dislocation of the radial head and dorsal dislocation of the distal radius, forming a criss-cross appearance of the ulna and radius on the lateral radiograph [1]. Unlike Essex-Lopresti injuries, the central band of the interosseous membrane (IOM) was believed to be intact with the proximal and distal IOM being simultaneously injured. However, the pathological changes and injury patterns were unclear and speculated only from radiographs and personal experiences. No exact proof has been provided in previous studies. In this case, additional MRI images and surgical findings provided clues to the pathological changes and injury patterns in this specific injury.

\section{Case presentation}

A 26-year-old woman presented to the emergency department immediately after a bicycle accident in which she fell on the ground with an outstretched hand. She complained of pain at her right wrist and elbow, especially when she rotated the forearm. On physical examination, the forearm was held in supination with the elbow in $90^{\circ}$ flexion and the wrist in the neutral position. A superficial abrasion was first noted on the palmar surface of the right wrist. Tenderness was triggered with direct palpation on the distal radio-ulnar joint (DRUJ), as well as the lateral and medial side of the elbow. No tenderness was detected with palpation on the middle portion of the forearm. The active range of motion of elbow joint was flexion $110^{\circ}$ /extension $180^{\circ}$, and rotation of forearm was supination $80^{\circ} /$ pronation $40^{\circ}$. She had a normal movement of the fingers and intact sensation in the right hand.

Radiographs of both forearms were taken for comparison, revealing volar dislocation of the radial head and dorsal dislocation of the distal radius without associated fracture on the injured side, which formed a criss-cross appearance on the lateral radiograph (Fig. 1). Computed Tomography (CT) scan was also applied to rule out associated fractures. To further evaluate the soft tissue injuries, Magnetic Resonance Imaging (MRI) of the forearm was taken, revealing partial rupture of the proximal IOM from its dorsal attachment and no impairment of the middle portion of the IOM, as well as partial rupture of the medial collateral ligament (MCL) (Fig. 2). Aside from ligamentous injuries, bone contusion was also detected on the capitellum of the humerus and the proximal ulna on MRI images.

The patient was first diagnosed as "Simultaneous dislocation of the radial head and distal radio-ulnar joint without fracture". We inclined not to diagnose this injury as an Essex-Lopresti injury because the central part of IOM seemed intact. Conservative treatment was firstly tried with closed reduction in the emergency room without anesthesia. With the elbow in $90^{\circ}$ flexion, the forearm was successively immobilized in either supination, pronation or neutral rotation with a long-arm cast. In each position, CT scan of the whole forearm was taken (Fig. 3). However, the radiocapitellar joint and the DRUJ could not be simultaneously reduced in either position.
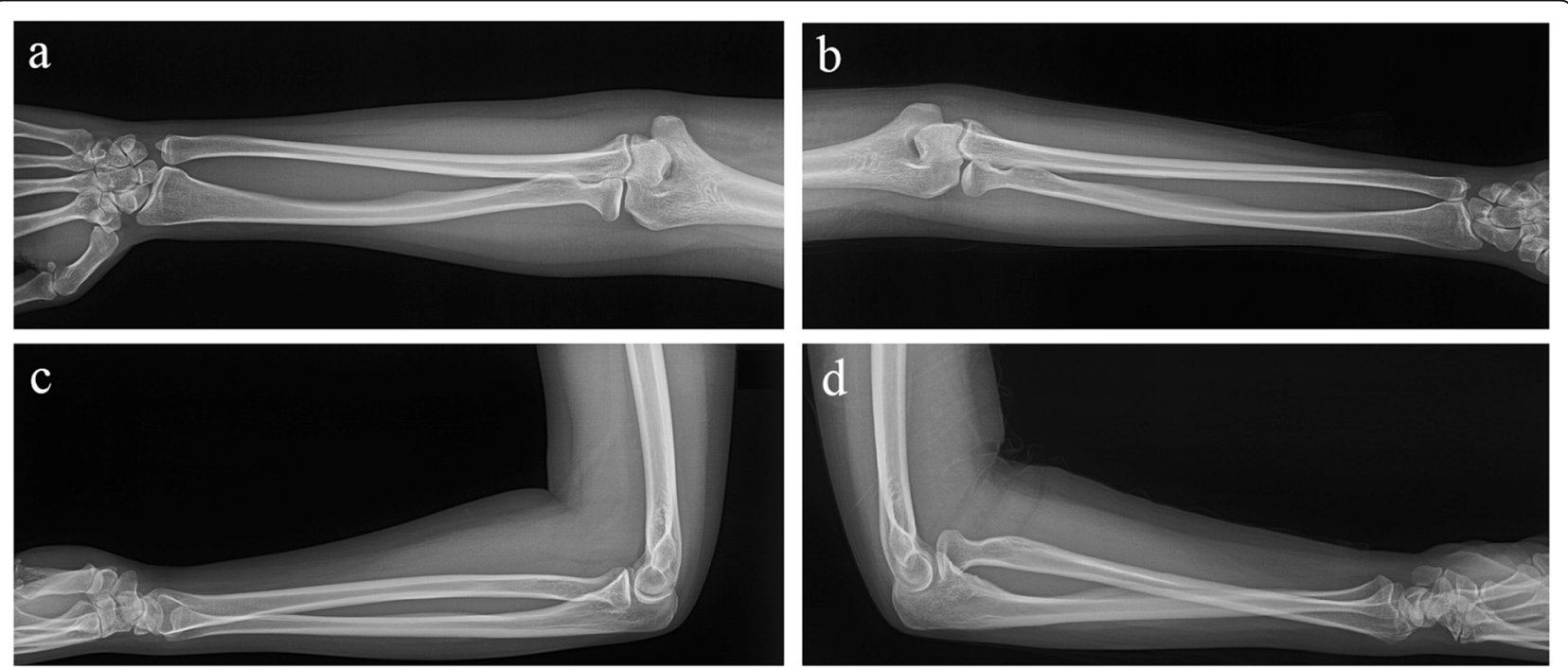

Fig. 1 Radiographs of the bilateral forearm. a: Anteroposterior view of the normal side; $\mathbf{b}$ : Anteroposterior view of the injured side; c: Lateral view of the normal side; $\mathbf{d}$ : Lateral view of the injured side demonstrating volar dislocation of the radial head and dorsal dislocation of the distal radius without associated fracture, thus forming a criss-cross appearance on the lateral radiograph 


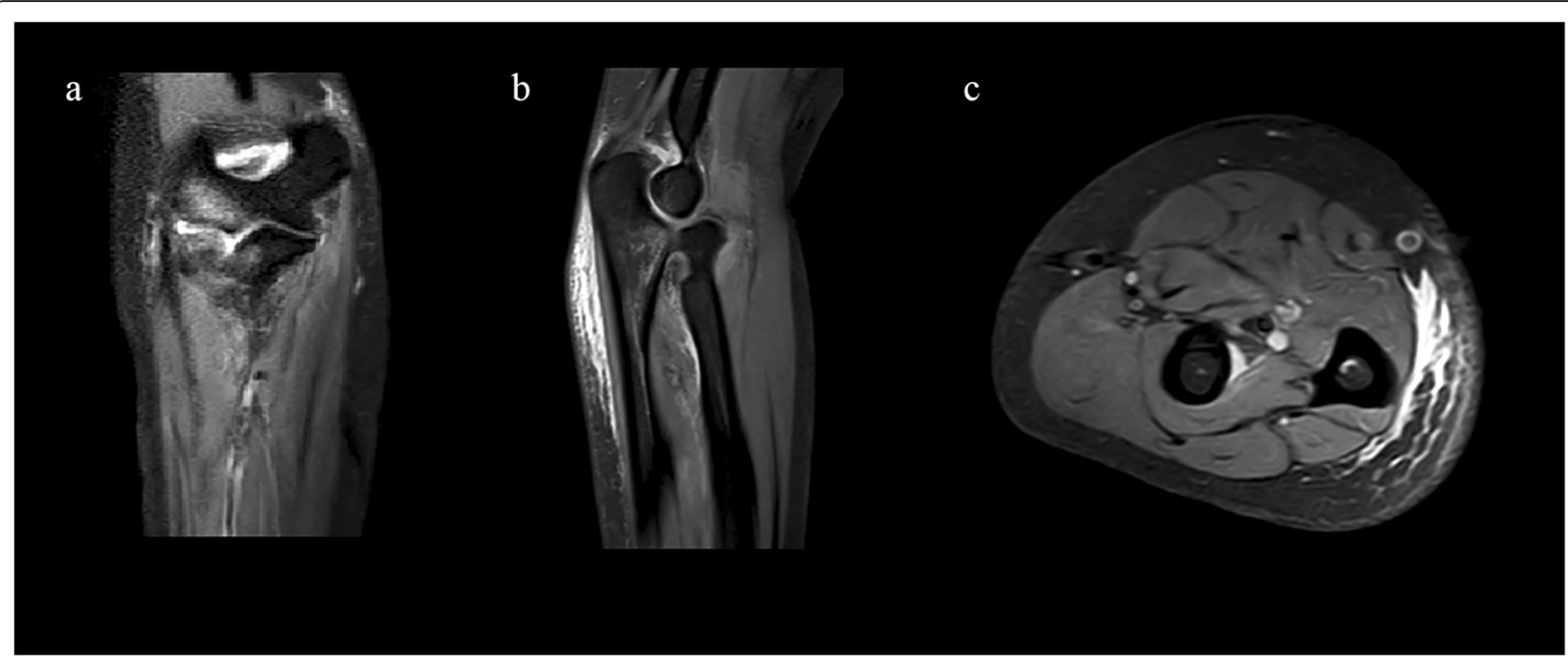

Fig. 2 Preoperative MRI images of the right forearm (MRI Sequence: PD_TSE_SPAIR). a: Coronal image shows bone contusion of the capitellum of the humerus and proximal ulna (White arrow), as well as partial rupture of the medial collateral ligament (Yellow arrow). b: Sagittal image shows high signal around the proximal IOM (Red arrow). c: Axial image shows rupture of the proximal IOM from the dorsal attachment (Red arrow). R: Radius; U: Ulna

The patient was then introduced to an expert in elbow surgery and advised to undergo surgical exploration. Before the surgery started, the stability of the elbow and the DRUJ were respectively tested under general anesthesia. During the Valgus Elbow Stress Test, the laxity of the elbow was increased and the radial head seemed to shift forward under a valgus force, indicating that the medial collateral ligament of the elbow and the annular ligament might be injured. The Ballottement Test also showed a positive result, revealing an unstable DRUJ.
After the examination, the surgery was performed, aiming to explore the lateral side of the elbow and repair the potentially injured annular ligament. A lateral approach of the elbow was performed. After dividing the subcutaneous tissues, the lateral collateral ligament revealed itself to be intact. Then, a longitudinal incision was made on the lateral collateral ligament to expose the annular ligament and the humeroradial joint. Surprisingly, the annular ligament was found to be perfectly intact, while the radial head was in a slightly anteriorly dislocated position. Further inspection of the radial head

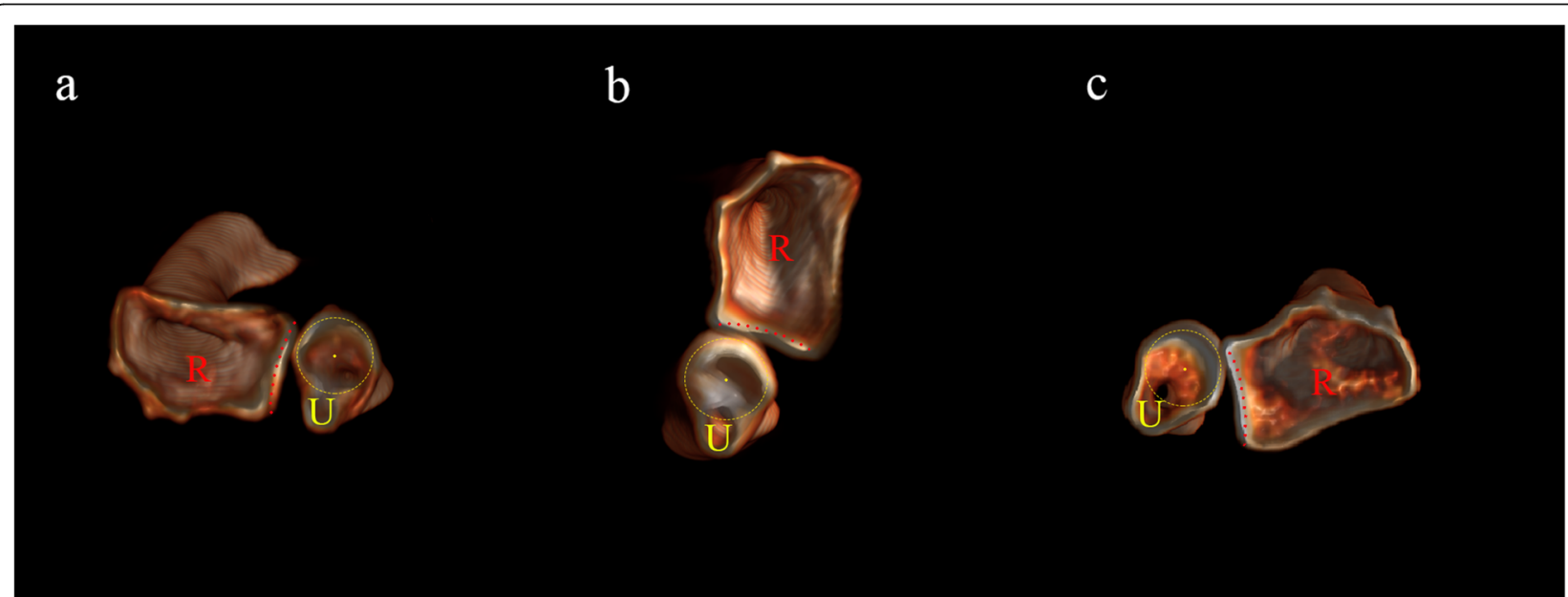

Fig. 3 Three dimensional CT reconstruction of the DRUJ with the forearm in different rotation position. a: The distal radius dislocated dorsally with the forearm in supination. b: The DRUJ was reduced with the forearm in neutral position. c: The distal radius dislocated palmarly with the forearm in pronation. Red dotted line: Sigmoid notch; Yellow dotted circle: Ulnar head; R: Radius; U: Ulna 


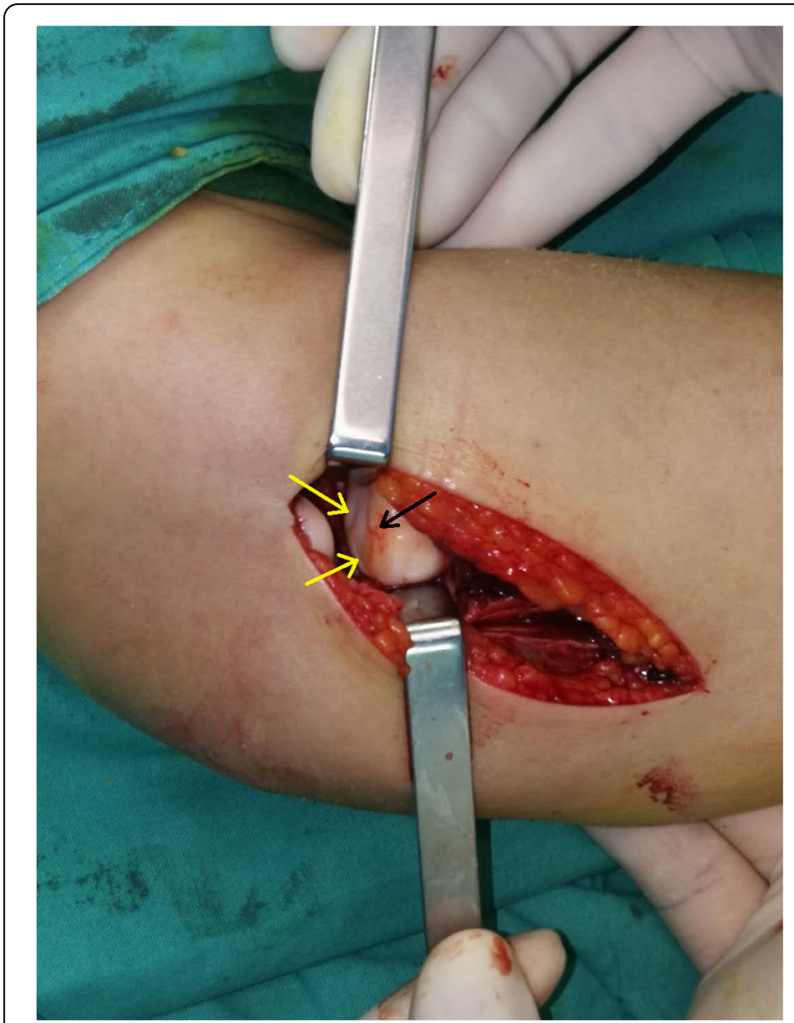

Fig. 4 Operative exploration revealed an abnormal radial head. Black arrow: Convex radial head. Yellow arrow: Bumpy articulation

revealed an abnormal, convex and bumpy articular surface (Fig. 4). An intraoperative Valgus Elbow Stress Test showed that the radial head would dislocate anteriorly under a valgus force. To reduce the radial head, rotation of the forearm was tried first and the results were not satisfying. So we apply a manual force upon the anterior part of the radial head to achieve a well-aligned reduction while the forearm was in full supination and the elbow was in $90^{\circ}$ flexion. Subsequently, a $2.0-\mathrm{mm}$ percutaneous K-wire was used to stabilize the proximal radioulnar joint (PRUJ). Intraoperative radiographs showed that the radial head and the DRUJ were simultaneously reduced (Fig. 5). After closing the wound, a long arm cast was used to keep the forearm in supination, $90^{\circ}$ of elbow flexion, and the wrist in neutral deviation.
The long arm cast was kept for 4 weeks and replaced by an adjustable brace to allow a full range of flexion and extension. The K-wire was removed at 6 weeks postoperatively to allow a full range of forearm rotation. At 6 months postoperatively, the patient had regained a full range of flexion and extension, with normal supination and a slight limitation in pronation. Until 18 months postoperatively, the patient still had a slight limitation in pronation, with the Mayo elbow score being 85 and the Mayo wrist score being 90(Fig. 6). Radiographic findings revealed that the radial head and the DRUJ were in better positions, but there was still a criss-cross appearance between radius and ulna on the lateral view (Fig. 7).

\section{Discussion and conclusion}

The injury of simultaneous dislocation of the radial head and the DRUJ without fracture was first introduced by Leung et al. [1] in 2002. They named this injury as a 'Criss-Cross' injury of the forearm, based on the ulna and radius forming a criss-cross appearance on the lateral radiograph. Until now, only 7 case reports were published about the 'Criss-Cross' injury. Among these case reports, 4 cases could be classified into severe types with complete dislocation of the radial head and the DRUJ [2-5], while the other 3 cases were less severe with subluxation of the radial head and DRUJ $[1,6,7]$. In our case, the patient also fell from the ground level and presented with a mild type of 'Criss-Cross' injury.

The pathologic changes of the 'Criss-Cross' injury were unclear in previous studies. The IOM of the forearm was believed to play the most important role in this injury [8]. Based on X-ray films and cadaveric studies, Leung et al. [1] hypothesized that the central band of the IOM might act as a pivot point between the radius and the ulna, producing paired rupture of the distal band and the proximal band. Unfortunately, the MRI did not cover the wrist so that the pathologic changes of the DRUJ and the distal IOM could not be confirmed.

The injury mechanism of 'Criss-Cross' injury was also ambiguous in previous studies. Bony contusion on the capitellum of the humerus and the proximal ulna indicated an axial and valgus force, while the proximal IOM being torn from the dorsal attachment of the radius
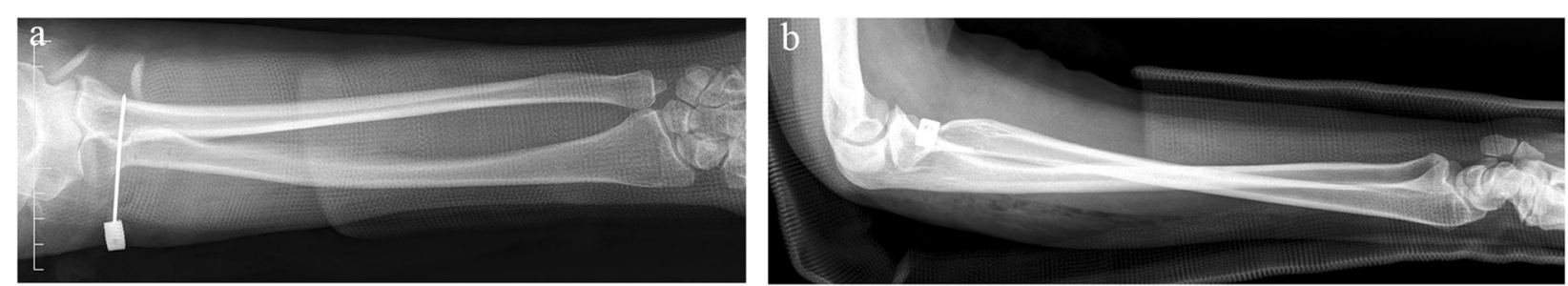

Fig. 5 Postoperative radiographs of the injured forearm. a: Anteroposterior view; b: Lateral view 

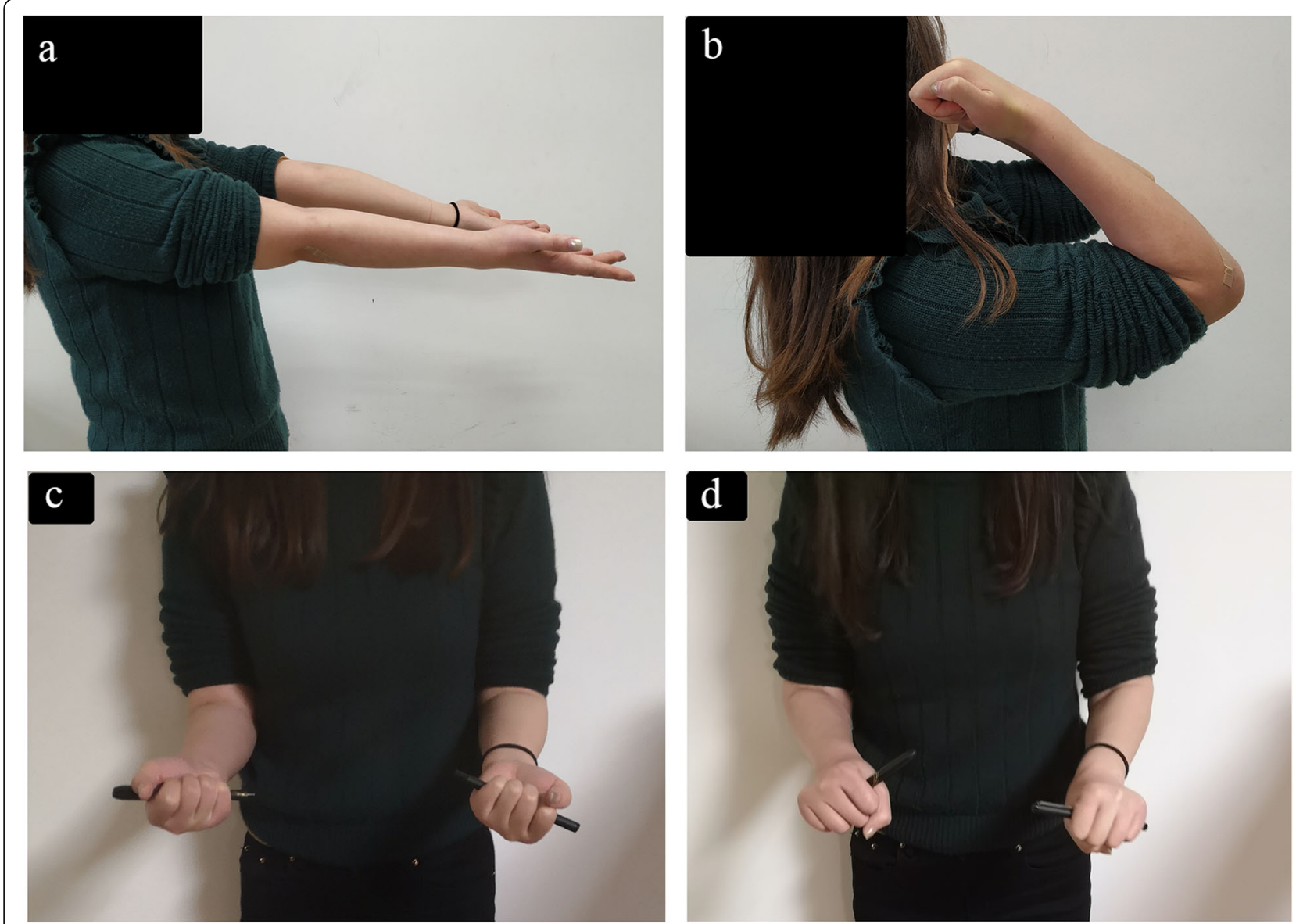

Fig. 6 Functional follow-up at 6 months postoperatively. a: Normal range of elbow extension. b: Normal range of elbow flexion. c: Normal range of supination. $\mathbf{d}$ : Slight limitation of pronation

indicated a pronated twisting force. According to a previous biomechanical study, the force across the central band of the IOM is nearly doubled with the forearm in neutral rotation as compared to supination or pronation with a constant axial load [9]. In other words, an axial load with the forearm in neutral rotation is more likely to disrupt the central band of IOM and create EssexLopresti injury. In contrast, a similar axial load with the forearm in hyperpronation might instead lead to rotation around the intact central band of the IOM and produce the paired dislocations in 'Criss-Cross' injuries. Normally, a radial head has a concave and smooth contour. However, in our case, CT scans and surgical findings revealed a convex and bumpy articular surface of the radial head. MRI images showed no obvious bony contusion or compressive fracture on the radial head, indicating that deformity might be an old injury. Similarly, Potter et al. [6] reported a chronic-appearing biconcave articular surface of the radial head with a midline ridge in their case. It was likely that the convex
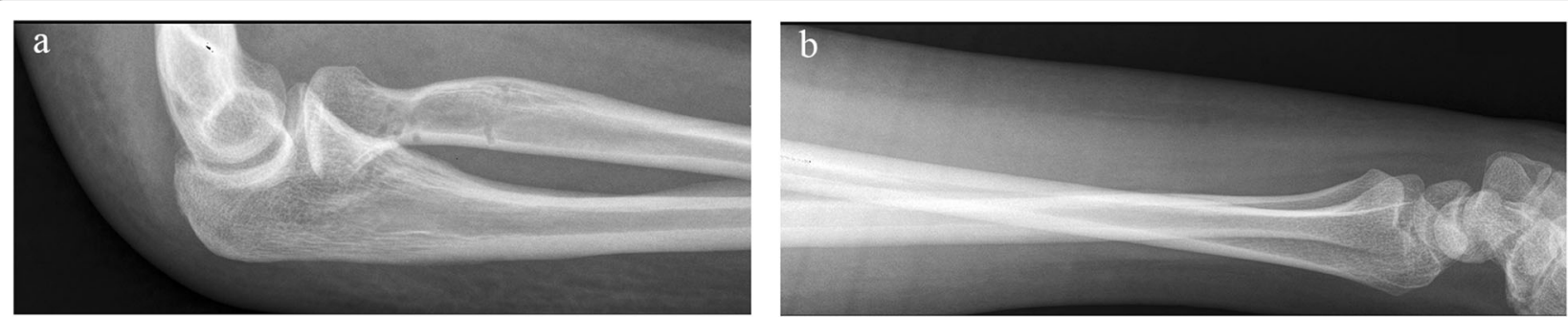

Fig. 7 Radiographic follow-up at 6 months postoperatively. a: Lateral view of the elbow shows normal alignment between capitellum and the radial head. b: Lateral view of the wrist shows a reduced DRUJ 
deformity of the radial head could disperse axial stress and transform it into transverse force, thus preventing radial head fracture and leading to radial head dislocation and rupture of the proximal IOM.

Simultaneous dislocation of the radial head and the DRUJ without fracture is a rare injury, and the pathologic changes and injury mechanism are unclear. This case demonstrates that the proximal IOM, especially the dorsal band, is injured in such injuries, while the central part of the IOM remains intact. This injury pattern distinguishes itself from Essex-Lopresti injury, which mainly involves rupture of the central band of the IOM.

\section{Supplementary information}

Supplementary information accompanies this paper at https://doi.org/10. 1186/s12893-020-00717-8.

\section{Additional file 1.}

Additional file 2 .

\section{Abbreviations}

DRUJ: Distal Radio-UInar Joint; PRUJ: Proximal Radio-Ulnar Joint: IOM: Interosseous Membrane; CT: Computed Tomography; MRI: Magnetic Resonance Imaging; MCL: Medial Collateral Ligament

\section{Acknowledgements}

Not applicable.

\section{Authors' contributions}

$\mathrm{XJ}$ and WZ were the patient's first-visit doctors, followed up the patient and contributed to manuscript drafting; YD reviewed the literatures and was responsible for the revision of the manuscript for important intellectual content; YH was the patient's surgeon, performed the surgery and was responsible for final approval of the version of the article to be published. All authors read and approved the final manuscript.

\section{Funding}

Not applicable.

\section{Availability of data and materials}

The datasets used during the current study are available from the corresponding author on reasonable request.

\section{Ethics approval and consent to participate}

The study was approved by the Ethics Committee of Shanghai Sixth People's Hospital and the patient gave her informed consent to participate.

\section{Consent for publication}

Written informed consent was obtained from the patient for publication of this case report and any accompanying images. A copy of the written consent is available for review by the Editor of this journal.

\section{Competing interests}

The authors declare that they have no competing interests.

Received: 21 April 2019 Accepted: 17 March 2020

Published online: 15 April 2020

\section{References}

1. Leung YF, Ip SP, Wong A, Wong KN, Wai YL. Isolated dislocation of the radial head, with simultaneous dislocation of proximal and distal radio-ulnar joints without fracture in an adult patient: case report and review of the literature. Injury. 2002;33:271-3.

2. Wong BL, Rama KB, Kumar A. Simultaneous dislocation of proximal and dista radio-ulnar joints: a case report. J Orthop Surg (Hong Kong). 2013;21:106-9.
3. Verettas DA, Drosos Gl, Xarchas KC, Chatzipapas CN, Staikos C. Simultaneous dislocation of the radial head and distal radio-ulnar joint. A case report. Int J Med Sci. 2008;29:292-4.

4. Tosun B, Selek O, Buluc L, Memisoglu K. Chronic post-traumatic radial head dislocation associated with dissociation of distal radio-ulnar joint: a case report. Arch Orthop Trauma Surg. 2008;128:669-71.

5. Nishi T, Suzuki N, Tani T, Aonuma H. Simultaneous dislocation of radiocapitellar and distal radioulnar joint. Case Rep Orthop. 2013;2013:106567.

6. Potter M, Wang A. Simultaneous dislocation of the radiocapitellar and distal radioulnar joints without fracture: case report. J Hand Surg [Am]. 2012:37:2502-5.

7. Spicer DD, Hargreaves D, Eckersley R. Simultaneous dislocations of the radiocapitellar and distal radioulnar joints. J Orthop Trauma. 2002;16:136-8.

8. Hayami N, Omokawa S, lida A, Kraisarin J, Moritomo H, Mahakkanukrauh P, Shimizu T, Kawamura K, Tanaka Y. Biomechanical study of isolated radial head dislocation. BMC Musculoskelet Disord. 2017;18:470.

9. Pfaeffle HJ, Fischer KJ, Manson TT, Tomaino MM, Woo SL, Herndon JH. Role of the forearm interosseous ligament: is it more than just longitudinal load transfer? J Hand Surg [Am]. 2000;25:683-8.

\section{Publisher's Note}

Springer Nature remains neutral with regard to jurisdictional claims in published maps and institutional affiliations.

Ready to submit your research? Choose BMC and benefit from:
- fast, convenient online submission
- thorough peer review by experienced researchers in your field
- rapid publication on acceptance
- support for research data, including large and complex data types
- gold Open Access which fosters wider collaboration and increased citations
- maximum visibility for your research: over 100M website views per year
At BMC, research is always in progress.
Learn more biomedcentral.com/submissions

